\title{
Beneficial effects of fermented vegetal beverages on human gastrointestinal microbial ecosystem in a simulator
}

\author{
Fernanda Bianchi ${ }^{\text {a,* }}$, Elizeu Antonio Rossi ${ }^{\text {a }}$, Isabel Kimiko Sakamoto ${ }^{\text {b }}$, Maria Angela Tallarico Adorno ${ }^{\text {, }}$ \\ Tom Van de Wiele ${ }^{c}$, Katia Sivieri ${ }^{\mathrm{a}}$ \\ a Department of Food and Nutrition, Probiotics Research Laboratory, Faculty of Pharmaceutical Sciences (UNESP), Araraquara, São Paulo, Brazil \\ ${ }^{\mathrm{b}}$ Laboratory of Biological Processes - LPB, School of Engineering of São Carlos - EESC/USP, São Carlos, São Paulo, Brazil \\ c Laboratory Microbial Ecology and Technology (LabMET), Ghent University, Coupure Links 653, B 9000 Gent, Belgium
}

\section{A R T I C L E I N F O}

\section{Article history:}

Received 15 March 2014

Accepted 30 May 2014

Available online 7 June 2014

\section{Keywords:}

SHIMER

Fermented beverage

Lactobacillus casei Lc-01

PCR-DGGE

SCFA

\begin{abstract}
A B S T R A C T
The aim of this study was to evaluate the effects of four beverage formulations (prebiotic - fructooligosaccharide, probiotic - Lactobacillus casei Lc-01, synbiotic - fructooligosaccharide and L. casei Lc-01 and placebo) based on aqueous extracts of soy and quinoa, towards the human intestinal microbiota using the Simulator of the Human Intestinal Microbial Ecosystem (SHIME®), a dynamic model of the human gut. To monitor the effects on microbial community composition, plate counts on specific growth media and a PCR-DGGE analysis were performed on samples from all colon compartments - ascending, transverse and descending. To verify the effects on microbial metabolism, we analyzed the ammonium and short chain fatty acids (SCFAs) concentrations. The synbiotic beverage showed the best microbiological results in the ascending colon compartment, stimulating the growth of Lactobacillus spp. and Bifidobacterium spp., and reducing Clostridium spp., Bacteroides spp., enterobacteria and Enterococcus spp. populations in this compartment. A larger reduction $(\mathrm{p}<0.05)$ of ammonia ions in the ascending colon was observed during the synbiotic beverage treatment. No statistical difference was observed in SCFA production among the treatments and the basal period. Plate count and DGGE analysis showed the survival of $L$. casei Lc-01 in the colon. DGGE analysis also showed higher richness and diversity of the Lactobacillus spp. community during the treatment with synbiotic beverage, with higher accentuation in the ascending colon.
\end{abstract}

(c) 2014 Elsevier Ltd. All rights reserved.

\section{Introduction}

The intestinal microbiota is a complex community of microorganisms that colonizes the gastrointestinal tract. About $10^{14}$ intestinal microbes belonging to $>1000$ different species-level phylogenetic types are distributed along the human gastrointestinal tract, with the highest densities reach in the colon (Frick \& Autenrieth, 2013; Payne, Zihler, Chassard, \& Lacroix, 2012; Rajilic-Stojanovic, Smidt, \& De vos, 2007).

Although the colonic microbiota is relatively stable throughout adult life, age-related changes in the gastrointestinal (GI) tract, as well as changes in diet and immune system reactivity, inevitably affect population composition (Woodmansey, 2007). Many efforts have focused on the modulation of the colonic microbiota and its metabolic activities in search of the community balance. The inclusion of foods containing prebiotics and probiotics in the daily diet can help to improve the gut health

\footnotetext{
* Corresponding author at: Faculty of Pharmaceutical Sciences (UNESP), $1 \mathrm{Km}$ JauAraraquara Highway, 14801-902, Araraquara, São Paulo, Brazil. Tel.: + 551633016932 +5516997744750.

E-mail address: febianchi@hotmail.com (F. Bianchi).
}

by increasing the number of beneficial bacteria and reducing the harmful ones, in addition to alleviate diarrhea symptoms (Possemiers, Marzorati, Verstraete, \& Van de Wiele, 2010).

However, 16S rRNA-based cataloguing of gut microbiota via highthroughput sequencing platforms does not provide information on the functionality of any species identified. Unraveling the complexity of microbe-microbe interactions and identifying niches central to gut fermentation depend on functional studies. In vitro gut fermentation models represent an innovative technological platform consisting of multiple model designs, which permit investigations on the existence of gut microbial species (Payne et al., 2012).

The Simulator of the Human Intestinal Microbial Ecosystem (SHIME®) is an in vitro system proven to be a very useful model for nutrition studies, in terms of analysis of the intestinal microbial community composition (Kontula et al., 2002; Molly, Vandewoestyne, Desmet, \& Verstraete, 1994; Possemiers et al., 2010; Sivieri et al., 2013). It is a fivestage sequential reactor system simulating the different parts of the gastrointestinal tract, based on the model developed by Molly et al. (1994), optimized by De Boever, Deplancke, and Verstraete (2000) and validated by Possemiers, Verthé, Uyttendaele, and Verstraete (2004). The SHIME harbors a stable microbial community, representative of the 
human gut microbiota, both in fermentation activity and in composition (Molly et al., 1994).

The beverages used in this study, prepared with aqueous extracts of quinoa and soy, were acidified by probiotic microorganisms and/or with added fructooligosaccharide (FOS). These beverages may contribute to the intestinal microbiota health, influenced by the probiotic and prebiotic action and the bioactive constituents of soy and quinoa. Besides having all the essential amino acids and fatty acids of high quality ( $\omega 6, \omega 3$ and $\omega 9$ ), quinoa is an excellent example of functional food that aims at lowering the risk of various diseases (Ando et al., 2002; Vega-Gálvez et al., 2010). In addition, it is free from cholesterol, lactose and gluten, as the soybean. The synbiotic beverage, based on aqueous extract of soy and quinoa, presents proper physicochemical composition, and good acceptability and provides high viability to the probiotic microorganism during storage. However, its action in the human intestinal microbiota has not been studied and proven yet (Bianchi et al., unpublished data). Therefore, the aim of this study was to investigate the capacity of the synbiotic, prebiotic, probiotic and placebo beverages, based on aqueous extract of soy and quinoa, to temporarily modulate the intestinal microbiota after oral administration using the SHIME $®$ reactor system. This paper also evaluates the viability of $L$. casei Lc-01 after the passage through simulated stomach and duodenum conditions.

\section{Material and methods}

\subsection{Production of quinoa and soy extracts}

Quinoa grains were washed and rubbed manually in water to remove the antinutritional components (saponins) and, consequently, reduce the bitter aftertaste. They were immersed in water $(55 \mathrm{~g} / \mathrm{L})$ and boiled for $10 \mathrm{~min}$. Later, the grains and water were blended to a homogeneous mixture, which was filtered on a $250 \mathrm{mu}$-mesh screen to obtain the extract.

The aqueous extract of soybean was produced by the Soy Derivative Development and Production Unit, UNIVERSOJA, at the Faculty of Pharmaceutical Sciences of UNESP (Araraquara, Brazil), as described by Rossi, Vendramine, Carlos, Pei, and Valdez (1999).

\subsection{Production of synbiotic, prebiotic, placebo and probiotic beverages}

The four beverages were produced with $30 \%$ aqueous extracts of quinoa and $70 \%$ soy extract ( $89.5 \%$ of the extracts mixture), $6 \%$ sucrose (União, Brazil), $0.8 \%$ soybean oil (Liza, Brazil), 1\% food grade lactose (Purac, Brazil), 0.14\% Recodan TM RS-B stabilizer (Danisco, Brazil) and 2.5\% milk powder (Molico, Brazil). All beverages were elaborated according to Rossi, Reddy, and Silva (1984), differing only in acidification form and FOS content (Table 1).

All beverages were pasteurized prior to microorganism inoculation or acidification. Lactic acid PA (85\%) was used to acidify the placebo and prebiotic beverage to $\mathrm{pH} 4.8$. In formulations with added FOS, $3 \%$ of fructooligosaccharides (FOS-SKL Pharma, Brazil) was used after the pasteurization.

A commercial lyophilized culture of Lactobacillus casei (Lc-01) was activated in a milk medium ( $10 \%$ milk, $1 \%$ glucose, $0.5 \%$ yeast extract) $(2 \% \mathrm{v} / \mathrm{v})$ and kept at $37{ }^{\circ} \mathrm{C}$ for $15 \mathrm{~h}$ (until the stationary phase) under aerobic conditions. Subsequently, $2 \%(\mathrm{v} / \mathrm{v})$ of activated culture

Table 1

Differences in the preparation of synbiotic, prebiotic, probiotic and placebo beverages.

\begin{tabular}{lll}
\hline Beverage & FOS & Acidification \\
\hline Synbiotic (TS) & + FOS & Acidified with L. casei Lc-01 \\
Prebiotic (Tpe) & + FOS & Artificially acidified \\
Probiotic (Tpo) & - FOS & Acidified with L. casei Lc-01 \\
Placebo (Tpa) & - FOS & Artificially acidified \\
\hline
\end{tabular}

$\left(10^{8} \mathrm{UFC} / \mathrm{mL}\right.$ ) was added to the synbiotic and probiotic beverages and incubated at $37^{\circ} \mathrm{C}$ until reaching $\mathrm{pH} 4.8$.

\subsection{Long-term SHIME run}

The SHIME (registered tradename from Ghent University and ProDigest) is a simulator of the human intestinal microbial ecosystem (Molly et al., 1994) in which environmental conditions ( $\mathrm{pH}$, residence time and temperature) are controlled (Table 2). It consists of five double-jacketed vessels simulating the stomach, the duodenum, and the ascending (R3), transverse (R4) and descending colon (R5) (Fig. 1).

The five reactor vessels were continuously stirred by means of a magnetic stirrer and the temperature was kept at $37{ }^{\circ} \mathrm{C}$. The system was maintained anaerobically through a daily $\mathrm{N}_{2}$ flushing of $30 \mathrm{~min}$. The pH culture of vessels 3, 4 and 5 was automatically adjusted by the addition of $\mathrm{NaOH} 1 \mathrm{M}$ or $\mathrm{HCl} 0.1 \mathrm{M}$ and $\mathrm{HCl} 1 \mathrm{M}$ for the stomach region (Molly et al., 1994; Possemiers et al., 2004). Peristaltic pumps a-d (Fig. 1) worked semi-continuously, while the remainder (e-g) worked continuously, simulating the gastrointestinal tract.

\subsection{Intestinal microbiota stabilization and experimental protocol}

The reactor setup and the composition of the liquid feed (Table 3), which entered the system three times per day, were previously described by Possemiers et al. (2004).

The three colon vessels of the SHIME system were inoculated with bacteria from a fecal sample of a healthy 26-year-old adult female with no history of antibiotic treatment six months prior to the study. Aliquots $(20 \mathrm{~g})$ of fresh fecal samples were diluted and homogenized with $100 \mathrm{~mL}$ of sterilized phosphate buffer $(0.1 \mathrm{M} / \mathrm{L}, \mathrm{pH}$ 6.5), containing $1 \mathrm{~g} / \mathrm{L}$ sodium thioglycolate as the reducing agent. The microbial inoculum was stabilized over two weeks (basal period) on a carbohydrate-based medium (liquid feed) and allowed to adapt to the specific environmental conditions of the ascending, transverse and descending colon, in terms of $\mathrm{pH}$ range, retention time and available carbon sources (Molly et al., 1994). After two weeks of stabilization, treatments with synbiotic, prebiotic, placebo and probiotic beverages were performed. The beverages were added along with the basal feed in a proportion equivalent to $10^{8} \mathrm{CFU} / \mathrm{mL}$ in the final mixture. The protocol began with two weeks of basal period followed by four weeks of treatment with synbiotic beverage (TS), two weeks of post treatment (PT) (when the passage of beverages was ceased, with only the liquid feed running in the system), two weeks of prebiotic beverage treatment (TPe), two weeks of treatment with the placebo beverage (TPa), ending with two weeks of probiotic beverage treatment (TPo). The complete protocol, based on Kontula et al. (2002), is shown in Fig. 2.

\subsection{Viability of the probiotics in the stomach and duodenum}

The viability of $L$. casei in the stomach and duodenum passages was assessed in a sequential batch experiment designed to simulate the conditions and residence time in these organs. The beverages were added along with the liquid feed, a liquid start matrix based on a complex feed, which is normally dosed to the SHIME in a proportion equivalent to $10^{8} \mathrm{CFU} / \mathrm{mL}$ in the final mixture (Possemiers et al., 2004).

Table 2

Values of volume, residence time and pH established in each of the reactors of the SHIME system.

Source: Possemiers et al. (2004).

\begin{tabular}{llll}
\hline Reactor & Volume $(\mathrm{mL})$ & Residence time $(\mathrm{h})$ & $\mathrm{pH}$ \\
\hline R1: stomach & 200 & 2.5 & $2.2-2.4$ \\
R2: duodenum & 200 & 4.0 & - \\
R3: ascending colon & 500 & 20.0 & $5.6-5.9$ \\
R4: transverse colon & 800 & 32.0 & $6.1-6.9$ \\
R5: descending colon & 600 & 24.0 & $6.6-6.9$ \\
\hline
\end{tabular}




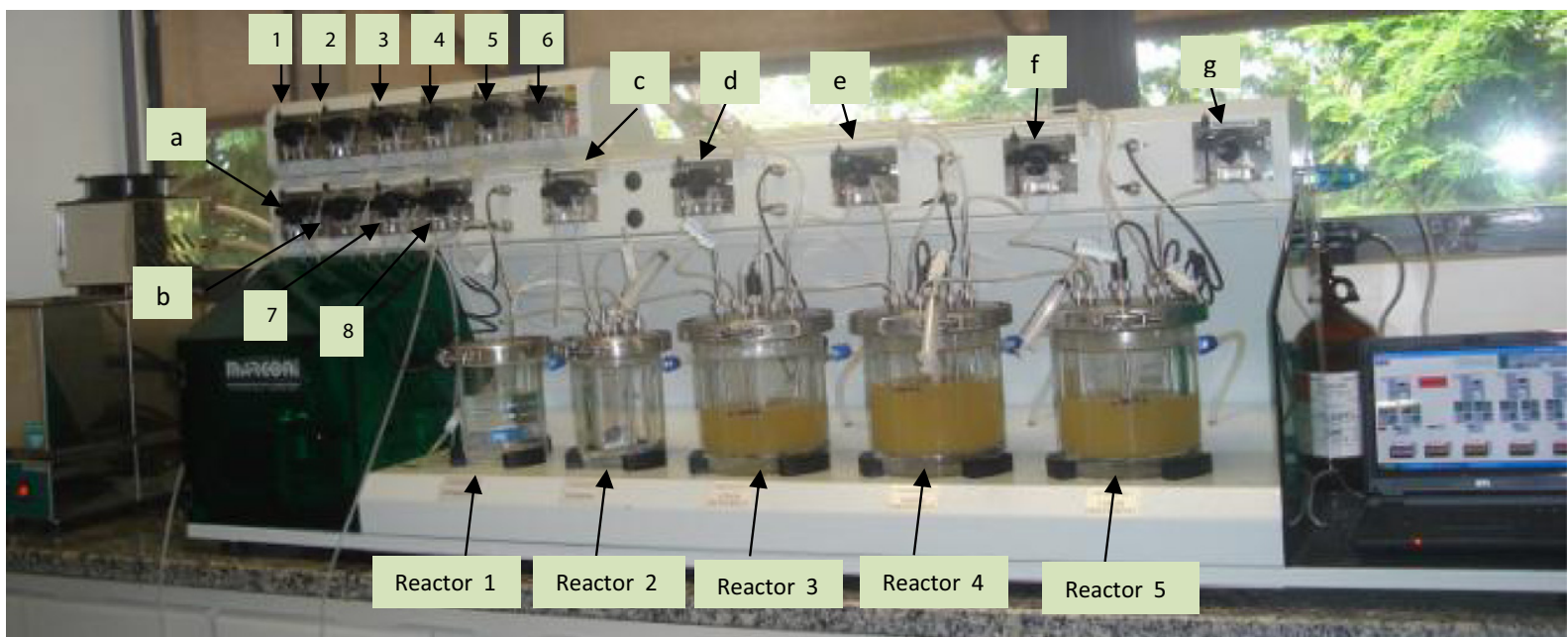

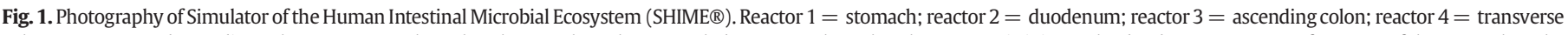

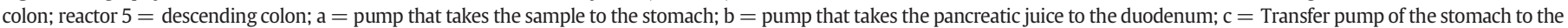

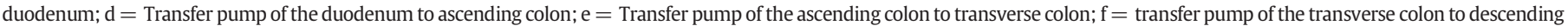

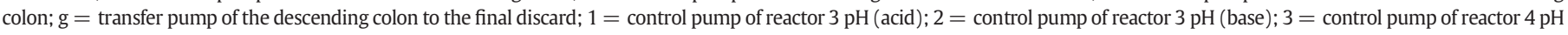

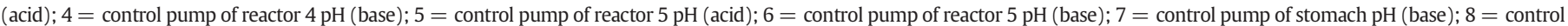
pump of stomach $\mathrm{pH}$ (acid).

The stomach environment was simulated at $\mathrm{pH} 2$ with $1 \mathrm{~g} / \mathrm{L}$ pepsin under microaerophilic conditions for $1.5 \mathrm{~h}$ at $37^{\circ} \mathrm{C}$. Pancreatic solution (per liter: $12.5 \mathrm{~g} \mathrm{NaHCO}_{3}, 6 \mathrm{~g}$ Oxgall and $0.9 \mathrm{~g}$ pancreatin) was added and incubated under anaerobic conditions for $2 \mathrm{~h}$ at $37{ }^{\circ} \mathrm{C}$ to simulate the duodenum environment. Before the start of the experiment and after half and complete incubation under respective stomach and duodenum conditions, a sample was taken for plate count analysis to assay the strain viability. One $\mathrm{mL}$ of each sample was suspended in $9 \mathrm{~mL}$ of peptone water. Serial dilutions were prepared and cultured on MRS Agar (Himedia, India) at $37{ }^{\circ} \mathrm{C} / 48 \mathrm{~h}$ under anaerobic conditions.

The evaluation of $L$. casei Lc-01 survival was also carried out using the culture-independent molecular method: polymerase chain reaction-denaturing gradient gel electrophoresis (PCR-DGGE). The used protocol is explained below.

\subsection{Microbiological analyses}

\subsubsection{Plate counts}

At weekly intervals, throughout the entire experimental period (basal, treatments and post-treatment), $5 \mathrm{~mL}$ samples were collected from the reactors for plate counts. The analysis of the intestinal microbiota composition was based on the enumeration of total aerobic and anaerobic bacteria, Enterococcus spp., Lactobacillus spp., Bifidobacterium spp., enterobacteria, Bacteroides spp. and Clostridium spp. One $\mathrm{mL}$ of a sample taken from each reactor was suspended in $9 \mathrm{~mL}$ of peptone

Table 3

Ingredients ( $\mathrm{g}$ ) employed for each liter of the liquid feed used in the SHIME reactor. Source: Payne et al.(2003).

\begin{tabular}{ll}
\hline Ingredients & Quantity $(\mathrm{g} / \mathrm{L})$ \\
\hline Starch (Maizena, Brasil) & 3.0 \\
Pectin (Vetec, Brasil) & 2.0 \\
Mucin (Sigma, USA) & 4.0 \\
Xylan (Sigma, USA) & 1.0 \\
Peptone (Acumedia, USA) & 1.0 \\
Arabinogalactan (Sigma, USA) & 1.0 \\
Glucose (Synth, Brasil) & 0.4 \\
Yeast extract (Acumedia, USA) & 3.0 \\
L-cysteine (Sigma, USA) & 0.5 \\
Sterile distilled water & Amount required to complete $1 \mathrm{~L}$ \\
\hline
\end{tabular}

water. Serial dilutions were prepared and inoculated into selective culture media, as shown in Table 4.

\subsubsection{Behavior and diversity of Lactobacillus spp. in the colon}

Molecular methods (PCR-DGGE) were used to analyze the behavior and diversity of the Lactobacillus spp. community through the entire experimental period.

The QIAamp DNA Stool Mini Kit (Qiagen, Germany) was employed to extract DNA from each reactor vessel, at each period of study and from the lyophilized culture of $L$ casei Lc-01. "Isolation of DNA from Stool for Human DNA" (QIAGEN, 2010) was the protocol used in this study with modifications in the amount of the initial sample $(220 \mathrm{mg}$ to $2 \mathrm{~mL}$ ) and AE buffer (200 mu to $50 \mathrm{mu}$ ). DNA yield was quantified using a NanoDrop ND-1000 spectrophotometer (NanoDrop Technologies, USA). The specific primers used as starting point for DNA replication were Lab159f ( $5^{\prime}$-GGAAACAGATGCTAATACCG-3') and Lab677GCr (5'GCCCGGGGCGCGCCCCGGGCGGG GCGGGGGCACGGGGGGGCACCG CTACACATGGAG-3') (Heilig et al., 2002). PCR was performed using the Taq polymerase (Invitrogen, Brazil). Samples were amplified in a Veriti ${ }^{\circledR}$ 96-well thermal cycler (Applied Biosystems, USA) by using the following program: initial denaturation at $94{ }^{\circ} \mathrm{C}$ for $2 \mathrm{~min}, 35$ cycles of denaturation at $94{ }^{\circ} \mathrm{C}$ for $30 \mathrm{~s}$, annealing of primer at $56{ }^{\circ} \mathrm{C}$ for $40 \mathrm{~s}$, elongation at $72{ }^{\circ} \mathrm{C}$ for $1 \mathrm{~min}$ and extension at $72{ }^{\circ} \mathrm{C}$ for $5 \mathrm{~min}$, followed by a final cooling to $4{ }^{\circ} \mathrm{C}$.

Electrophoresis was carried out as previously described (Heilig et al., 2002 ) in an $8 \%$ polyacrylamide gel with a denaturant gradient of $30-50 \%$ for $16 \mathrm{~h}$ at $85 \mathrm{~V}$ in a $0.5 \times \mathrm{TAE}$ buffer at a constant temperature of $60{ }^{\circ} \mathrm{C}$. Gels were stained with ethidium bromide according to Sanguinetti, Dias Neto, and Simpson (1994), scanned at 400 d.p.i., and further analyzed by the BioNumerics 6.0 software (Applied Maths, Kortrijk, Belgium).

The distance matrices of each DGGE based on the Jaccard similarity coefficient to cluster the samples, were analyzed using the BioNumerics 6.0 software (Applied Maths, Kortrijk, Belgium).

\subsubsection{Ecological interpretation of fingerprint of Lactobacillus spp. population}

Ecological interpretation of fingerprint (range-weighted richness and functional organization) was conducted as suggested by Marzorati, Wittebolle, Boon, Daffonchio, and Verstraete (2008).

The range-weighted richness $(R r)$ is correlated with the distribution of the bands in the DGGE pattern and the percentage denaturant 


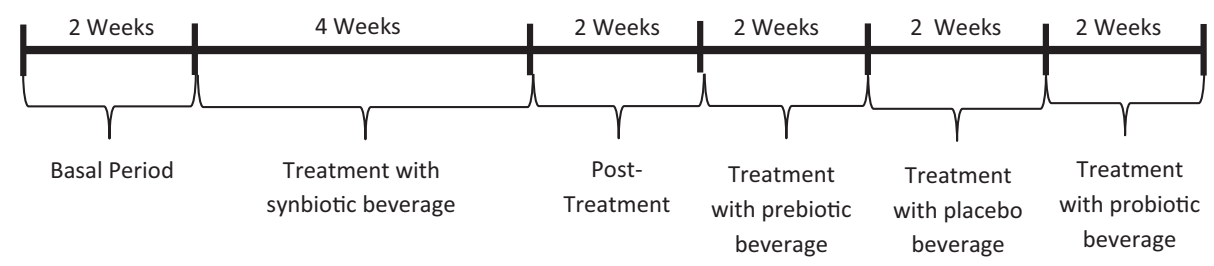

Fig. 2. Experimental SHIME® protocol.

gradient of the gel needed to represent the sample's total diversity (within the limits of the technique). This concept can be mathematically expressed by defining an $R r$ index $=\left(\mathrm{N}^{2} \times \mathrm{Dg}\right)$, where $\mathrm{N}$ represents the total number of bands in the pattern, and Dg the denaturing gradient comprised between the first and the last band of the pattern (Marzorati et al., 2008).

The functional organization (Fo) is the result of the action of the microorganisms that are most fitting to the ongoing environmentalmicrobiological interactions (Marzorati et al., 2008). Pareto-Lorenz distribution curves were created to graphically represent the uniformity of Lactobacillus spp. communities, based on DGGE profile and evaluated on the $20 \%$ level of the $\mathrm{x}$ axis, as previously described (Lorenz, 1905; Mertens, Boon, \& Verstraete, 2005; Wittebolle, Vervaeren, Verstraete, \& Boon, 2008).

\subsection{Ammonium analysis}

Samples were collected once a week from the vessels for ammonium analysis, throughout the entire experimental period (basal, treatments and post-treatment). The ammonia content was determined using a selective ion meter (710A model, Orion) coupled to an ammonia selective-ion electrode (Orion 95-12). The apparatus was calibrated using $0.1 \mathrm{M}$ standard ammonium chloride solutions, at 10,100 , and $1000 \mathrm{mg} / \mathrm{L}$ of ammonia. A total of $0.5 \mathrm{~mL}$ ISA solution (Ionic Strength Adjuster, Orion), a pH-adjusting and ionic force solution, was added to every $25 \mathrm{~mL}$ of sample. All measurements were carried out at $25{ }^{\circ} \mathrm{C}$ (Bedani, 2008). The analyses were performed in triplicate.

\subsection{Analysis of short-chain fatty acids (SCFAs)}

Samples were collected weekly from the reactors for SCFA analysis throughout the entire experimental period (basal, treatments and post-treatment). The analyses were carried out in triplicate and the samples were frozen at $-20{ }^{\circ} \mathrm{C}$. The SCFAs were determined using a gas chromatograph equipped with a flame-ionization gas detector, a capillary split/splitless injector and a HP-INNOWAX column with a $30 \mathrm{~m} \times 0.25 \mathrm{~mm} \times 0.25 \mu \mathrm{m}$ inlet (Shimadzu GC2010). Hydrogen was the carrier gas at a flow rate of $1.56 \mathrm{~mL} / \mathrm{min}$. The temperatures of the column, injector and detector were 170,250 and $280{ }^{\circ} \mathrm{C}$, respectively (Van de Wiele, Boon, Possemiers, Jacobs, \& Verstraete, 2007).

\subsection{Statistical analysis}

The significance of all results was investigated with one-way ANOVA, and individual means were compared using the Tukey's test ( $p<0.05$ ), using the Sigma Stat 5.0 software (Systat Software Inc., San Jose, California).

\section{Results and discussion}

\subsection{Viability of the probiotic in the stomach and duodenum}

Plate counts showed an enhanced protection of $L$. casei Lc-01 with the synbiotic beverage. There was no decrease in $L$. casei Lc-01 viability under stomach conditions during the treatment with the synbiotic beverage, although a reduction of $1 \log \mathrm{CFU} / \mathrm{mL}$ was observed under duodenum conditions (Fig. 3). In the treatment with the probiotic beverage, a significant reduction in the viability of $L$. casei was observed under stomach and duodenum conditions, indicating that the association between the probiotic microorganism and prebiotic FOS provides a positive effect on $L$. casei Lc-01 survival under acid conditions (Fig. 3).

Malolactic fermentation and histidine accumulation were revealed as important features of acid adaptation in L. casei. Malolactic enzyme was upregulated 16-fold and 7-fold following 5 and 20 min of acid exposure, respectively. This enzyme functions to decarboxylate L-malate to L-lactate and $\mathrm{CO}_{2}$, thus contributing to cytoplasm alkalization (Mills, Stanton, Fitzgerald, \& Ross, 2011).

Guergoletto, Magnani, Martin, Andrade, and Garcia (2010) affirm that $L$. casei Lc-01 has good resistance to the gastric and enteric juices. According to Mishra and Prasad (2005), the ability to tolerate acid and pancreatic juice can vary from one strain to another. Pozza, Miglioranza, Garcia, Garcia, and Pozza (2011) studied different Lactobacillus strains isolated from feces of children and confirmed eight strains resistant to acidic conditions and bile salts.

Xanthopoulos, Litopoulou-Tanetaki, and Tzanetakis (2000) affirm that bile salt resistance tends to vary between the lactic acid bacteria and among strains of same species. According to Gilliland (1987) and Saarela, Mogensen, Fondén, Matto, and Mattila-Sandholm (2000), bile salts are toxic to cells because they disrupt the cellular membrane structure and, therefore, bile salt tolerance is considered one of the required characteristics for the survival of lactic acid bacteria in the duodenum. Despite the reduction of $L$. casei $\mathrm{Lc}-01$ population $(1 \log \mathrm{CFU} / \mathrm{mL}$ ) after the passage of the microorganism through the duodenum, in both synbiotic and probiotic beverages, $L$. casei preserved the viability

Table 4

Culture medium and culture conditions used in plate count analysis.

\begin{tabular}{|c|c|c|c|c|c|}
\hline Genus & Culture medium & Brand & Time/temperature & Oxygen condition & Reference \\
\hline Lactobacillus & MRS agar & Himedia (India) & $37^{\circ} \mathrm{C} / 48 \mathrm{~h}$ & Anaerobiosis & Yoshioka, Iseki, and Fujita (1983) \\
\hline Bifidobacterium & Bifido Medium BIM-25 & Difco (France) & $37^{\circ} \mathrm{C} / 72 \mathrm{~h}$ & Anaerobiosis & Munoa and Pares (1988) \\
\hline Clostridium & RCA agar & Difco (France) & $37^{\circ} \mathrm{C} / 48 \mathrm{~h}$ & Anaerobiosis & Marzotto et al. (2006) \\
\hline Enterobacteia & MacConkey agar & Acumedia (USA) & $37^{\circ} \mathrm{C} / 48 \mathrm{~h}$ & Anaerobiosis & Brigidi, Vitali, Swennen, Bazzocchi, and Matteuzzi (2001) \\
\hline Enterococcus & KF Streptococcus agar & Acumedia (USA) & $37^{\circ} \mathrm{C} / 48 \mathrm{~h}$ & Aerobiose & Edlund et al. (2000) \\
\hline Bacteroides & BE agar & Acumedia, (USA) & $37^{\circ} \mathrm{C} / 120 \mathrm{~h}$ & Anaerobiosis & Livingston, Kominos, and Yee (1978) \\
\hline Total anaerobes & Standard methods agar & Acumedia (USA) & $37^{\circ} \mathrm{C} / 48 \mathrm{~h}$ & Anaerobiosis & Yoshioka et al. (1983) \\
\hline Facultative aerobes & Standard methods agar & Acumedia (USA) & $37^{\circ} \mathrm{C} / 48 \mathrm{~h}$ & Aerobiose & Yoshioka et al. (1983) \\
\hline
\end{tabular}




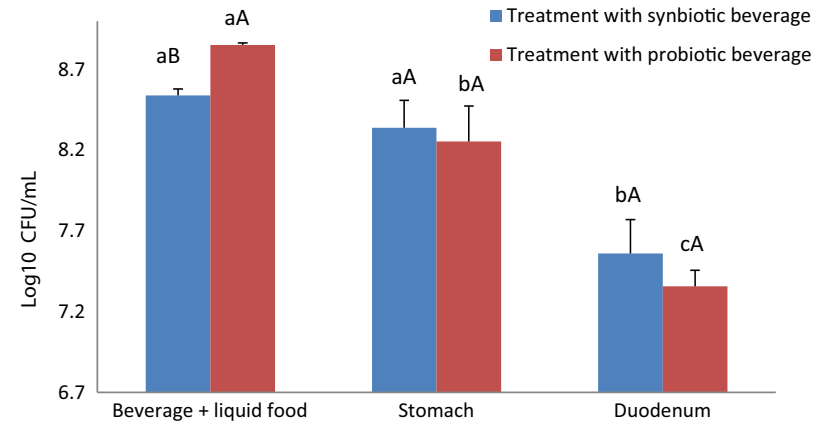

Fig. 3. L. casei population ( $\log \mathrm{CFU} / \mathrm{mL})$ in synbiotic and probiotic beverages with added liquid feed and under stomach and duodenum conditions. Different lowercase letters represent a significant difference ( $\mathrm{p} \leq 0.05$ ) in $L$. casei population to the same treatment between the two compartments and the liquid feed added to beverage, whereas different uppercase letters represent a significant difference $(\mathrm{p} \leq 0.05)$ in $L$. casei population between the treatments.

upon entering the first colon compartment, maintaining an average of $7.45 \pm 0.14 \log \mathrm{CFU} / \mathrm{mL}$.

DGGE fingerprints for lactobacilli (Fig. 4) indicated that L. casei Lc-01 survived the stomach and duodenum conditions and, subsequently, reached the colon during the experiment period. In the last two weeks of the treatment with synbiotic beverages (TS3 and TS4), there was an intensification of the bands that ran in the same position of the pure L. casei Lc-01 culture (Fig. 4a). The inverse occurred in the posttreatment (PT1 and PT2), when the passage of synbiotic beverage was ceased. Fig. 4b shows that the appearance of equivalent bands to
L. casei Lc-01 (control) is observed only when the treatment was performed with the probiotic beverages (TPo). When the prebiotic (Tpe) and placebo (TPa) beverages were analyzed, it is clear that few or no band is visualized running in the same position of pure L. casei Lc-01 culture. According to Capela, Hay, and Shah (2006), the prebiotics provide extra solids, which tend to protect cells from injury. Oligosaccharides used in this study are hydrocolloids, which play a protective role towards probiotic microorganisms (Desai, Powell, \& Shah, 2004). This way, the microorganism can provide its probiotic beneficial effects more effectively.

\subsection{L. casei Lc-01 capacity to temporarily colonize the colon in the SHIME experiment}

As reflected in the plate count data (Table 5), the administration of the synbiotic beverage to the system induced a significant increase $(p<0.05)$ in lactobacilli counts, with a concentration increase of at least $1 \mathrm{log} \mathrm{CFU} / \mathrm{mL}$ in the ascending colon compartment. There was an increase of Bifidobacterium spp. and a decrease of Clostridium spp., Bacteroides spp., enterobacteria and Enterococcus spp. populations. Regarding the other beverages, a decrease in Enterococcus spp., Clostridium spp. and enterobacteria was observed. However, the results were more significant $(p<0.05)$ in the treatment with synbiotic beverage, both in relation to the increase of beneficial bacteria and the reduction of pathogenic ones.

DGGE analysis was used to monitor qualitative changes in the composition and structure of the microbial communities in the three compartments simulating colon conditions. The dendrograms from the ascending (R3), transverse (R4) and descending colon (R5) showed

(a)

R3 (Ascending colon)

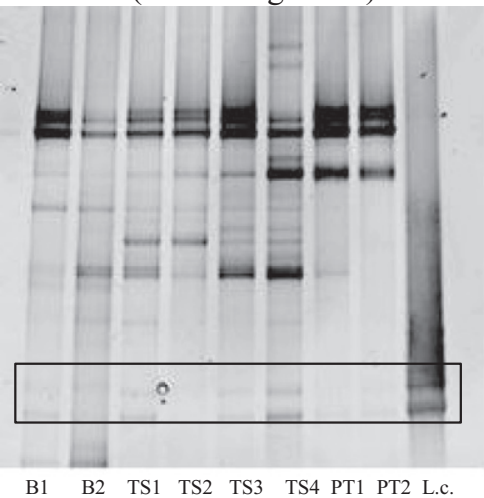

(b)

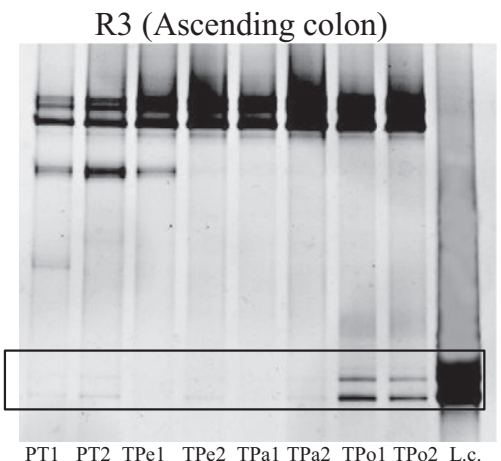

R4 (Transverse colon)

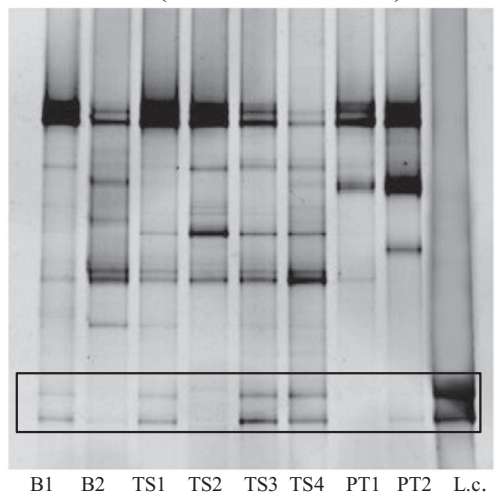

R5 (Descending colon)

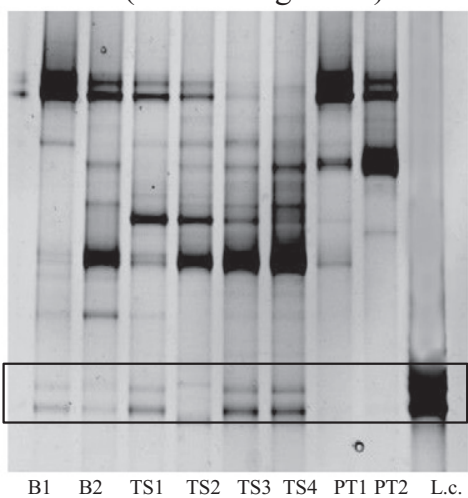

B1 B2 TS1 TS2 TS3 TS4 PT1 PT2 L.c.

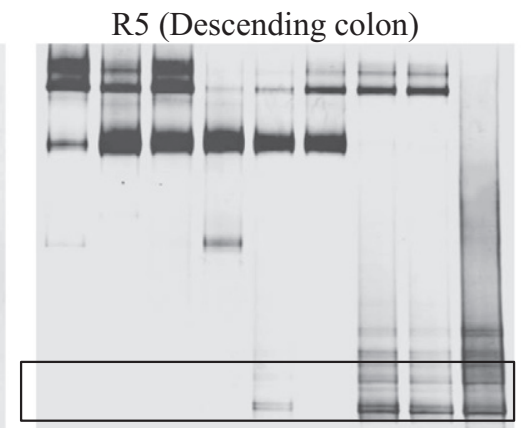

PT1 PT2 TPe1 TPe2 TPa1 TPa2 TPo1 TPo2 L.c.

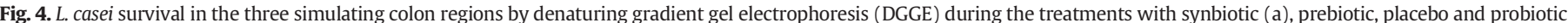

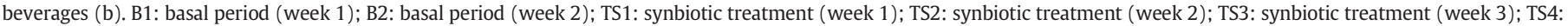

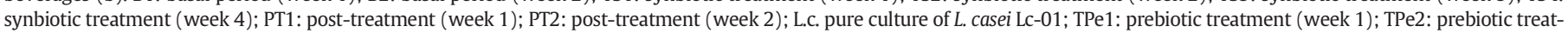
ment (week 2); TPa1: placebo treatment (week 1); TPa2: placebo treatment (week 2); TPo1: probiotic treatment (week 1); TPo2: probiotic treatment (week 2). 
Table 5

Average plate count measurements ( \pm SEM), expressed in log CFU/mL, for the different microbial groups, SHIME® compartments and periods.

\begin{tabular}{|c|c|c|c|c|c|c|}
\hline & B & TS & PT & Tpe & $\mathrm{TPa}$ & TPo \\
\hline \multicolumn{7}{|l|}{ R3 (Ascending colon) } \\
\hline Lactobacillus spp. & $7.88 \pm 0.06^{\mathrm{C}}$ & $8.39 \pm 0.02^{\mathrm{A}}$ & $8.40 \pm 0.03^{A}$ & $7.29 \pm 0.08^{\mathrm{D}}$ & $8.04 \pm 0.02^{\mathrm{B}}$ & $8.11 \pm 0.07^{\mathrm{B}}$ \\
\hline Bifidobacterium spp. & $7.75 \pm 0.00^{C}$ & $8.21 \pm 0.01^{\mathrm{B}}$ & $8.44 \pm 0.02^{\mathrm{A}}$ & $7.48 \pm 0.01^{\mathrm{D}}$ & $7.31 \pm 0.10^{\mathrm{E}}$ & $7.82 \pm 0.06^{\mathrm{C}}$ \\
\hline Clostridium spp. & $8.44 \pm 0.04^{\mathrm{A}}$ & $8.02 \pm 0.00^{\mathrm{BC}}$ & $8.35 \pm 0.01^{\mathrm{AB}}$ & $7.01 \pm 0.01^{\mathrm{D}}$ & $8.66 \pm 0.01^{\mathrm{A}}$ & $7.97 \pm 0.01^{\mathrm{C}}$ \\
\hline Enterococcus spp. & $7.45 \pm 0.21^{\mathrm{B}}$ & $4.73 \pm 0.07^{\mathrm{D}}$ & $8.77 \pm 0.01^{\mathrm{A}}$ & $6.66 \pm 0.08^{C}$ & $7.86 \pm 0.09^{\mathrm{B}}$ & $6.53 \pm 0.28^{C}$ \\
\hline Enterobacteria & $9.23 \pm 0.07^{\mathrm{A}}$ & $7.45 \pm 0.03^{\mathrm{C}}$ & $7.61 \pm 0.06^{\mathrm{B}}$ & $7.09 \pm 0.00^{\mathrm{D}}$ & $7.19 \pm 0.07^{\mathrm{D}}$ & $5.79 \pm 0.04^{\mathrm{E}}$ \\
\hline Total aerobes & $8.20 \pm 0.07^{\mathrm{A}}$ & $7.74 \pm 0.03^{\mathrm{B}}$ & $8.39 \pm 0.03^{A}$ & $7.68 \pm 0.05^{\mathrm{B}}$ & $7.27 \pm 0.02^{\mathrm{C}}$ & $7.80 \pm 0.02^{\mathrm{B}}$ \\
\hline Facultative anaerobes & $8.13 \pm 0.05^{\mathrm{C}}$ & $7.68 \pm 0.05^{\mathrm{D}}$ & $8.89 \pm 0.03^{A}$ & $7.23 \pm 0.11^{\mathrm{E}}$ & $8.59 \pm 0.05^{\mathrm{B}}$ & $8.06 \pm 0.02^{C}$ \\
\hline Bacteroides & $4.94 \pm 0.05^{\mathrm{B}}$ & $2.58 \pm 0.11^{\mathrm{D}}$ & $4.43 \pm 0.02^{\mathrm{B}}$ & $5.46 \pm 0.05^{\mathrm{A}}$ & $5.47 \pm 0.12^{\mathrm{A}}$ & $4.04 \pm 0.16^{\mathrm{C}}$ \\
\hline \multicolumn{7}{|l|}{ R4 (Transverse colon) } \\
\hline Lactobacillus spp. & $7.82 \pm 0.02^{\mathrm{A}}$ & $7.04 \pm 0.03^{\mathrm{BC}}$ & $6.91 \pm 0.02^{C}$ & $7.40 \pm 0.33^{\mathrm{B}}$ & $6.36 \pm 0.10^{\mathrm{D}}$ & $7.01 \pm 0.01^{\mathrm{C}}$ \\
\hline Bifidobacterium spp. & $7.56 \pm 0.00^{\mathrm{A}}$ & $7.02 \pm 0.02^{\mathrm{B}}$ & $7.10 \pm 0.03^{\mathrm{B}}$ & $6.82 \pm 0.09^{C}$ & $5.06 \pm 0.11^{\mathrm{E}}$ & $6.30 \pm 0.02^{\mathrm{D}}$ \\
\hline Clostridium spp. & $8.24 \pm 0.04^{\mathrm{A}}$ & $7.26 \pm 0.13^{\mathrm{CD}}$ & $7.40 \pm 0.06^{\mathrm{C}}$ & $7.11 \pm 0.05^{\mathrm{D}}$ & $7.93 \pm 0.04^{\mathrm{B}}$ & $6.85 \pm 0.04^{\mathrm{E}}$ \\
\hline Enterococcus spp. & $7.09 \pm 0.08^{B}$ & $4.61 \pm 0.04^{\mathrm{E}}$ & $7.98 \pm 0.07^{\mathrm{A}}$ & $6.90 \pm 0.22^{\mathrm{B}}$ & $6.16 \pm 0.15^{C}$ & $5.42 \pm 0.12^{\mathrm{D}}$ \\
\hline Enterobacteria & $7.69 \pm 0.13^{A}$ & $6.19 \pm 0.03^{\mathrm{D}}$ & $7.09 \pm 0.04^{\mathrm{B}}$ & $7.46 \pm 0.10^{\mathrm{A}}$ & $6.40 \pm 0.08^{\mathrm{D}}$ & $6.62 \pm 0.05^{\mathrm{C}}$ \\
\hline Total aerobes & $7.76 \pm 0.09^{\mathrm{A}}$ & $7.77 \pm 0.08^{A}$ & $7.52 \pm 0.00^{\mathrm{A}}$ & $7.15 \pm 0.14^{\mathrm{B}}$ & $7.44 \pm 0.24^{\mathrm{AB}}$ & $6.68 \pm 0.01^{\mathrm{C}}$ \\
\hline Facultative anaerobes & $7.82 \pm 0.02^{\mathrm{A}}$ & $6.87 \pm 0.01^{\mathrm{BC}}$ & $7.90 \pm 0.09^{A}$ & $6.87 \pm 0.22^{\mathrm{BC}}$ & $5.75 \pm 0.02^{\mathrm{D}}$ & $6.66 \pm 0.05^{\mathrm{C}}$ \\
\hline Bacteroides & $7.39 \pm 0.01^{\mathrm{B}}$ & $7.65 \pm 0.07^{\mathrm{B}}$ & $7.30 \pm 0.09^{\mathrm{B}}$ & $8.68 \pm 0.26^{\mathrm{A}}$ & $8.63 \pm 0.27^{\mathrm{A}}$ & $7.73 \pm 0.27^{\mathrm{B}}$ \\
\hline \multicolumn{7}{|l|}{ R5 (Descending colon) } \\
\hline Lactobacillus spp. & $7.90 \pm 0.06^{\mathrm{A}}$ & $6.50 \pm 0.03^{\mathrm{B}}$ & $6.40 \pm 0.09^{\mathrm{B}}$ & $6.23 \pm 0.15^{\mathrm{B}}$ & $5.62 \pm 0.29^{C}$ & $6.29 \pm 0.08^{\mathrm{B}}$ \\
\hline Bifidobacterium spp. & $7.44 \pm 0.07^{\mathrm{A}}$ & $7.00 \pm 0.01^{\mathrm{B}}$ & $6.63 \pm 0.00^{c}$ & $6.10 \pm 0.13^{\mathrm{D}}$ & $5.22 \pm 0.16^{\mathrm{F}}$ & $5.54 \pm 0.27^{\mathrm{E}}$ \\
\hline Clostridium spp. & $8.24 \pm 0.04^{\mathrm{A}}$ & $7.26 \pm 0.13^{C}$ & $7.69 \pm 0.01^{\mathrm{B}}$ & $6.73 \pm 0.13^{\mathrm{D}}$ & $8.14 \pm 0.24^{\mathrm{A}}$ & $6.47 \pm 0.08^{\mathrm{D}}$ \\
\hline Enterococcus spp. & $7.21 \pm 0.28^{\mathrm{A}}$ & $4.94 \pm 0.16^{\mathrm{EC}}$ & $6.50 \pm 0.01^{\mathrm{B}}$ & $5.59 \pm 0.38^{\mathrm{CD}}$ & $5.48 \pm 0.20^{\mathrm{DC}}$ & $5.02 \pm 0.21^{\mathrm{DE}}$ \\
\hline Enterobacteria & $7.73 \pm 0.11^{\mathrm{A}}$ & $6.77 \pm 0.06^{\mathrm{B}}$ & $6.50 \pm 0.22^{\mathrm{BD}}$ & $5.40 \pm 0.41^{\mathrm{C}}$ & $6.14 \pm 0.09^{\mathrm{D}}$ & $6.49 \pm 0.09^{\mathrm{BD}}$ \\
\hline Total aerobes & $7.65 \pm 0.13^{\mathrm{A}}$ & $7.27 \pm 0.64^{\mathrm{B}}$ & $7.47 \pm 1.03^{\mathrm{A}}$ & $6.97 \pm 0.29^{C}$ & $6.23 \pm 0.97^{\mathrm{E}}$ & $6.60 \pm 0.11^{\mathrm{D}}$ \\
\hline Facultative anaerobes & $6.79 \pm 0.08^{\mathrm{A}}$ & $6.79 \pm 0.05^{\mathrm{A}}$ & $6.88 \pm 0.00^{A}$ & $6.97 \pm 0.10^{\mathrm{A}}$ & $6.85 \pm 0.02^{\mathrm{B}}$ & $6.99 \pm 0.07^{\mathrm{A}}$ \\
\hline Bacteroides & $7.78 \pm 0.05^{\mathrm{BC}}$ & $8.00 \pm 0.11^{\mathrm{B}}$ & $7.35 \pm 0.02^{C}$ & $8.14 \pm 0.06^{\mathrm{B}}$ & $8.45 \pm 0.28^{\mathrm{A}}$ & $8.14 \pm 0.34^{\mathrm{B}}$ \\
\hline
\end{tabular}

Different uppercase letters in the same line represent statistical difference $(\mathrm{p}<0.05)$ between the treatments for the same reactor. B: basal period. TS: treatment with synbiotic beverage, PT: Post-treatment, Tpe: treatment with prebiotic beverage, Tpo: treatment with probiotic beverage and TPa: treatment with placebo beverage.

the formation of two major groups: from the synbiotic treatment (ST) and other from the prebiotic, probiotic and placebo treatments, which formed group I (Fig. 5). This division into two major groups with low similarity ( 20\%) shows different Lactobacillus species in the SHIME reactor (Marzorati et al., 2010) during the different treatments and, therefore, changes in the Lactobacillus spp. community, particularly in the synbiotic beverage treatment. The synbiotic beverage stimulated the growth of several species of Lactobacillus in all reactors, which did not occur with the other treatments. Fig. 4a shows an increase in the number of bands in the three reactors along the treatment with synbiotic beverage. In contrast, there was a decrease in the number of bands during the post-treatment and treatment with other beverages (Fig. 4b). Similar results were found by Sivieri, Bianchi, and Rossi (2011) and
Van de Wiele, Boon, Possemiers, Jacobs and Verstraete (2004), who reported beneficial effects of probiotics and prebiotics, respectively, in the three colon regions, limited to the treatment period, thus requiring continuous consumption of the studied component to obtain the beneficial effects. In addition, effect of probiotics on the growth of colon lactobacilli was elucidated by a study of Chaikham and Apichartsrangkoon (2014), who showed that the oral administration of the encapsulated Lactobacillus acidophilus LA5 along with pasteurized longan juice stimulated a significant increase of lactobacilli ( $\geq 2 \mathrm{log}$ cycle) in all colon compartments in SHIME reactor. Molly, De Smet, Nollet, De Woestyne, and Verstraete (1996) showed that the quantities of colon lactobacilli significantly increased by $10^{8} \mathrm{CFU} /$ day after feeding probiotics to the SHIME reactor.
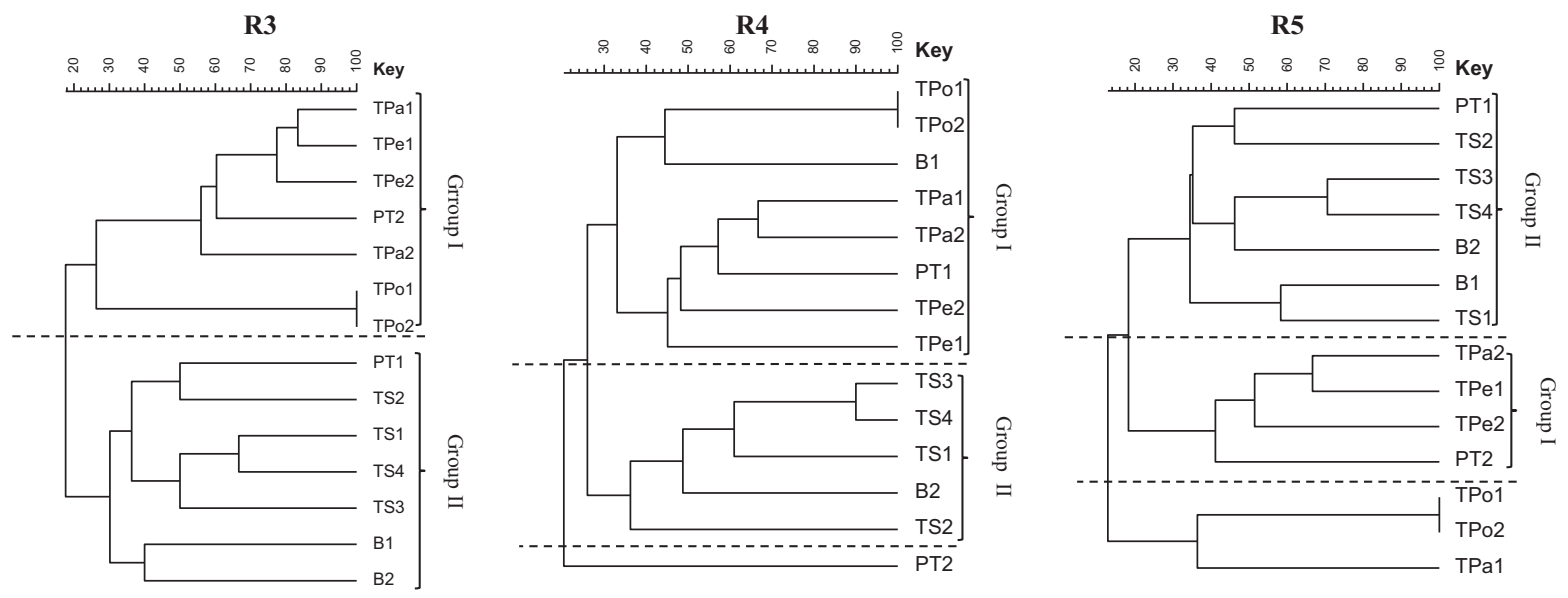

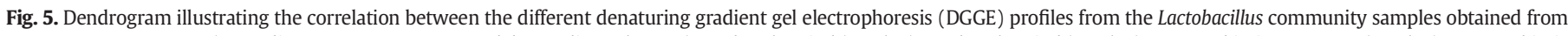

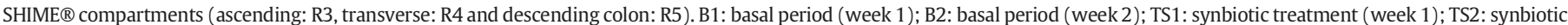

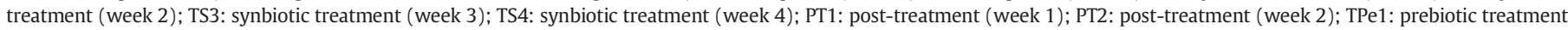

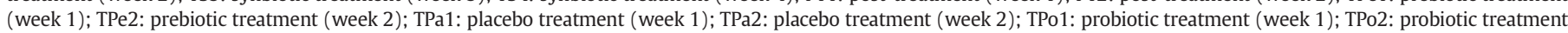
(week 2). 


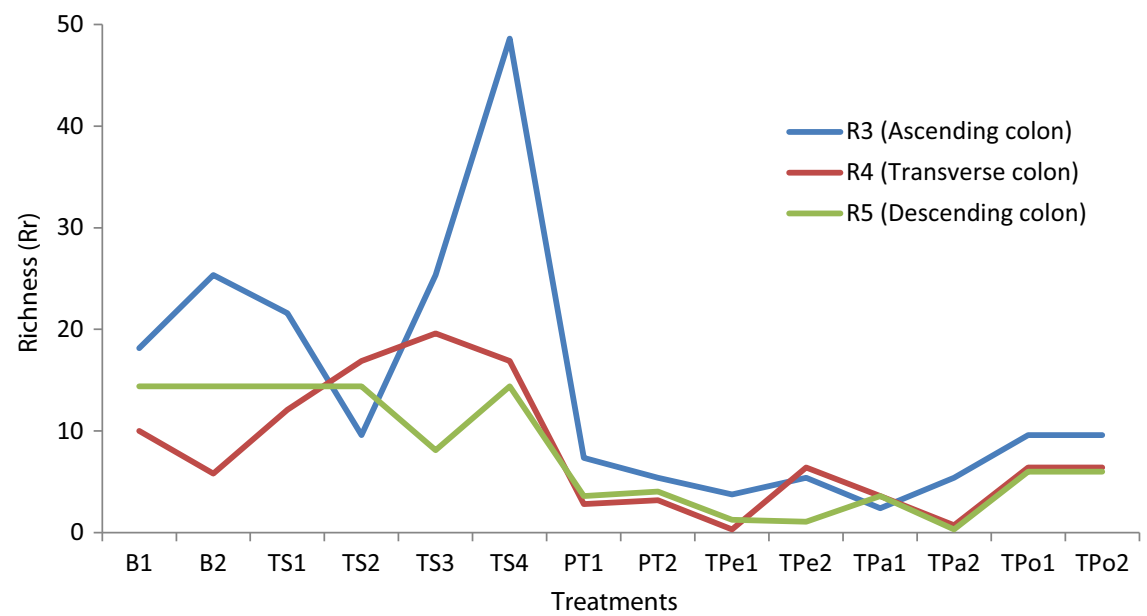

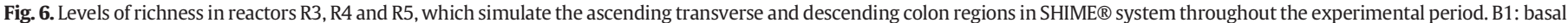

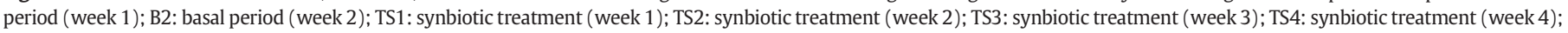

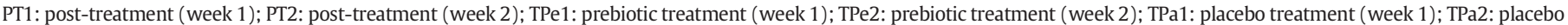
treatment (week 2); TPo1: probiotic treatment (week 1); TPo2: probiotic treatment (week 2).

\subsection{Effects of the long-term treatment on the lactobacilli community structure}

There was a greater enrichment of lactobacilli population when the treatment was carried out with the synbiotic beverage, both in the ascending and transverse colons. There is no difference in the descending colon when compared to the basal period (Fig. 6). According to Marzorati et al. (2008), $R r$ values below 10 indicate a low-richness population, whereas $R r$ values between 10 and 30 and above 30 indicate medium and high-richness populations, respectively, in terms of entire community. The latter is characterized as a typical population of very healthy environments, with a high microbial diversity (Marzorati et al., 2008). This way, it is possible to say that R3 provided a healthier environment when treated with synbiotic beverage than other reactors, resulting in a high-richness of lactobacilli and changing the diversity of this population in a positive way. $\mathrm{R} 4$ also resulted in a richness increase
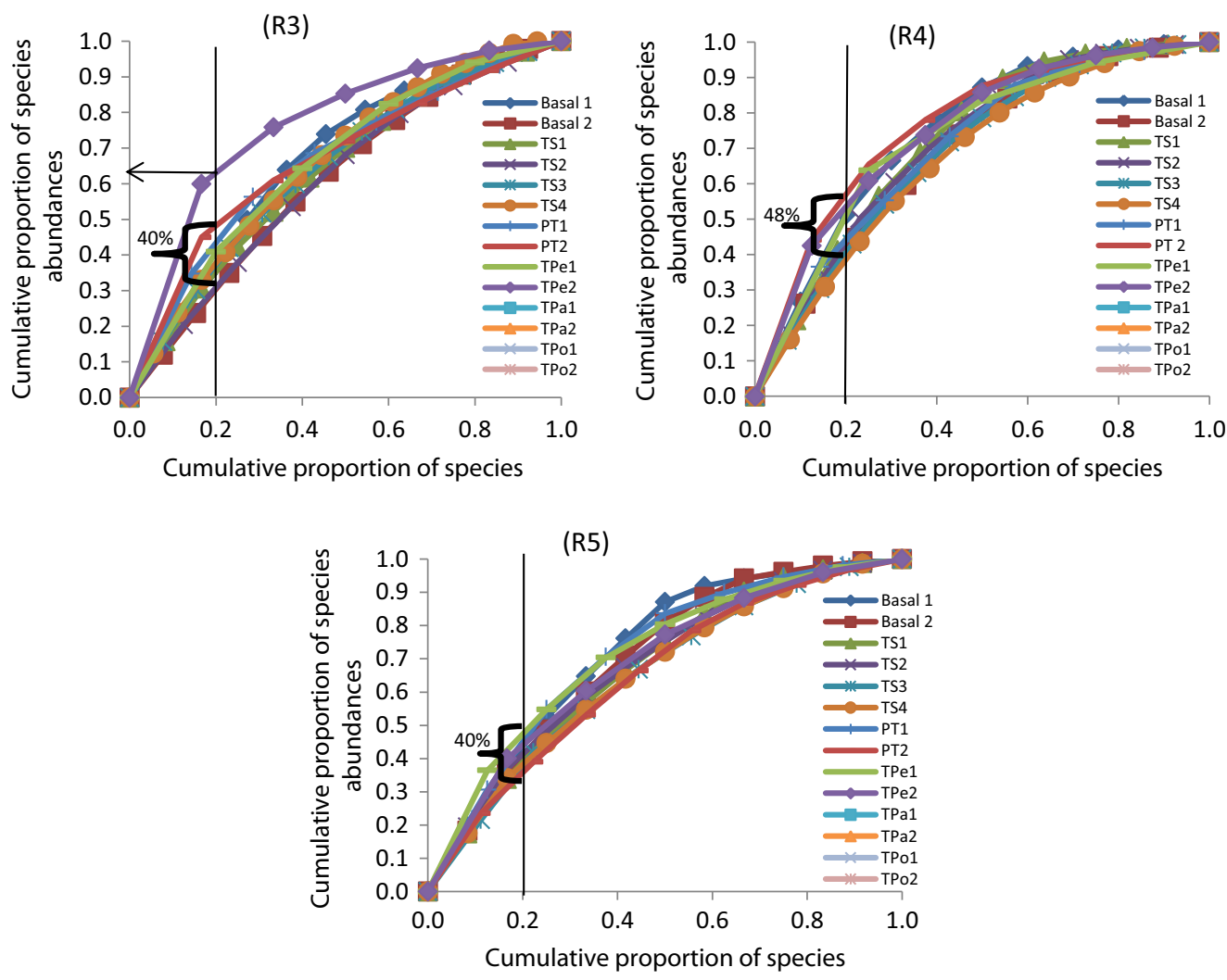

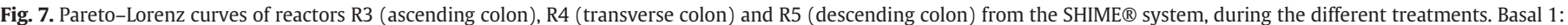

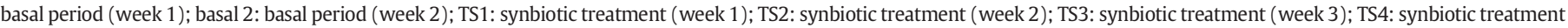

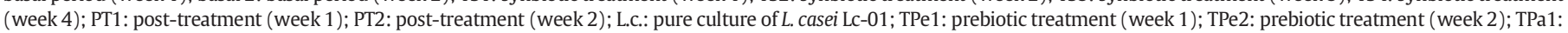
placebo treatment (week 1); TPa2: placebo treatment (week 2); TPo1: probiotic treatment (week 1); TPo2: probiotic treatment (week 2). 
Table 6

Average ammonium ion production (ppm) in SHIME® run during the different treatments.

\begin{tabular}{llll}
\hline & Ascending colon & Transverse colon & Descending colon \\
\hline Basal period & $580.91 \pm 109.71^{\mathrm{A}}$ & $614.91 \pm 60.22^{\mathrm{A}}$ & $680.58 \pm 49.38^{\mathrm{A}}$ \\
Synbiotic treatment & $65.30 \pm 14.05^{\mathrm{C}}$ & $311.13 \pm 25.15^{\mathrm{B}}$ & $434.41 \pm 44.43^{\mathrm{B}}$ \\
Post-treatment week 1 & $95.20 \pm 7.46^{\mathrm{C}}$ & $252.00 \pm 6.24^{\mathrm{B}}$ & $360.66 \pm 8.32^{\mathrm{B}}$ \\
Post- treatment week 2 & $508.66 \pm 20.30^{\mathrm{A}}$ & $593.00 \pm 17.57^{\mathrm{A}}$ & $663.3 \pm 15.27^{\mathrm{A}}$ \\
Prebiotic treatment & $255.83 \pm 140.24^{\mathrm{B}}$ & $565.50 \pm 101.12^{\mathrm{A}}$ & $639.17 \pm 28.05^{\mathrm{A}}$ \\
Placebo treatment & $277.66 \pm 12.66^{\mathrm{B}}$ & $664.00 \pm 17.34^{\mathrm{A}}$ & $732.33 \pm 24.17^{\mathrm{A}}$ \\
Probiotic treatment & $332.66 \pm 0.70^{\mathrm{B}}$ & $588.33 \pm 16.50^{\mathrm{A}}$ & $693.50 \pm 46.90^{\mathrm{A}}$ \\
\hline
\end{tabular}

Different uppercase letters in the same column represent statistical difference $(p<0.05)$ between the different treatments.

of lactobacilli species, but this contribution was lower than that provided by R3. No changes were observed in R5 richness during the treatment with synbiotic beverage.

These results were expected because the $\mathrm{pH}$ in the colon (between 5.6 and 5.9) favors the growth of Lactobacillus spp., which explains the higher richness of Lactobacillus spp. in the R3 reactor (Sivieri et al., 2011).

In addition to the analysis on Lactobacillus spp. community richness, a Pareto-Lorenz (PL) curve was also built, seeking a better understanding of lactobacilli population behavior and its functionality in the different treatments.

Except for the treatment with the prebiotic beverage at week 2 (TPe2) in R3, which showed a distance point from the other treatments, there was an average of functionality coefficient value of $43 \%$ between the reactors. There were no great changes in the functionality of a reactor to another and from one treatment to another (Fig. 7).
According to Marzorati et al. (2008) and Carballa, Smits, Etchebehere, Boon, and Verstraete (2011), in terms of entire community, low (20-25\%) and high (>80\%) PL curves indicate a highly uniform and specialized community, respectively. Consequently, a long lag phase could be needed to counteract a sudden stress. A PL curve between 45 and $60 \%$ represents balanced communities, which can potentially deal with changing environmental conditions while preserving their functionality.

In view of this, it is possible to classify the lactobacilli population in the three colon regions during different treatments, as a balanced community, capable of surviving at different environmental conditions while maintaining its functionality. It indicates that even with the increase or decrease of Lactobacillus species (proven by dependent and independent methods of cultivation) and other bacterial genera, in accordance with the used treatment, there were no major changes in the Lactobacillus spp. functional organization. Therefore, this population remained stable and balanced throughout the study.

\subsection{Ammonium ions}

A significant reduction in ammonia ions production in all reactors during the treatment with synbiotic beverage, with greater intensity in ascending colon, was observed. These values remained low until the first week after this treatment, with a large increase only in the second week of post-treatment, but no higher than the control period value (Table 6). This result is considered beneficial because ammonia can alter the morphology and the intermediary metabolism of intestinal cells by increasing DNA synthesis and promoting colon carcinogenesis (Ichikawa \& Sakata, 1998).
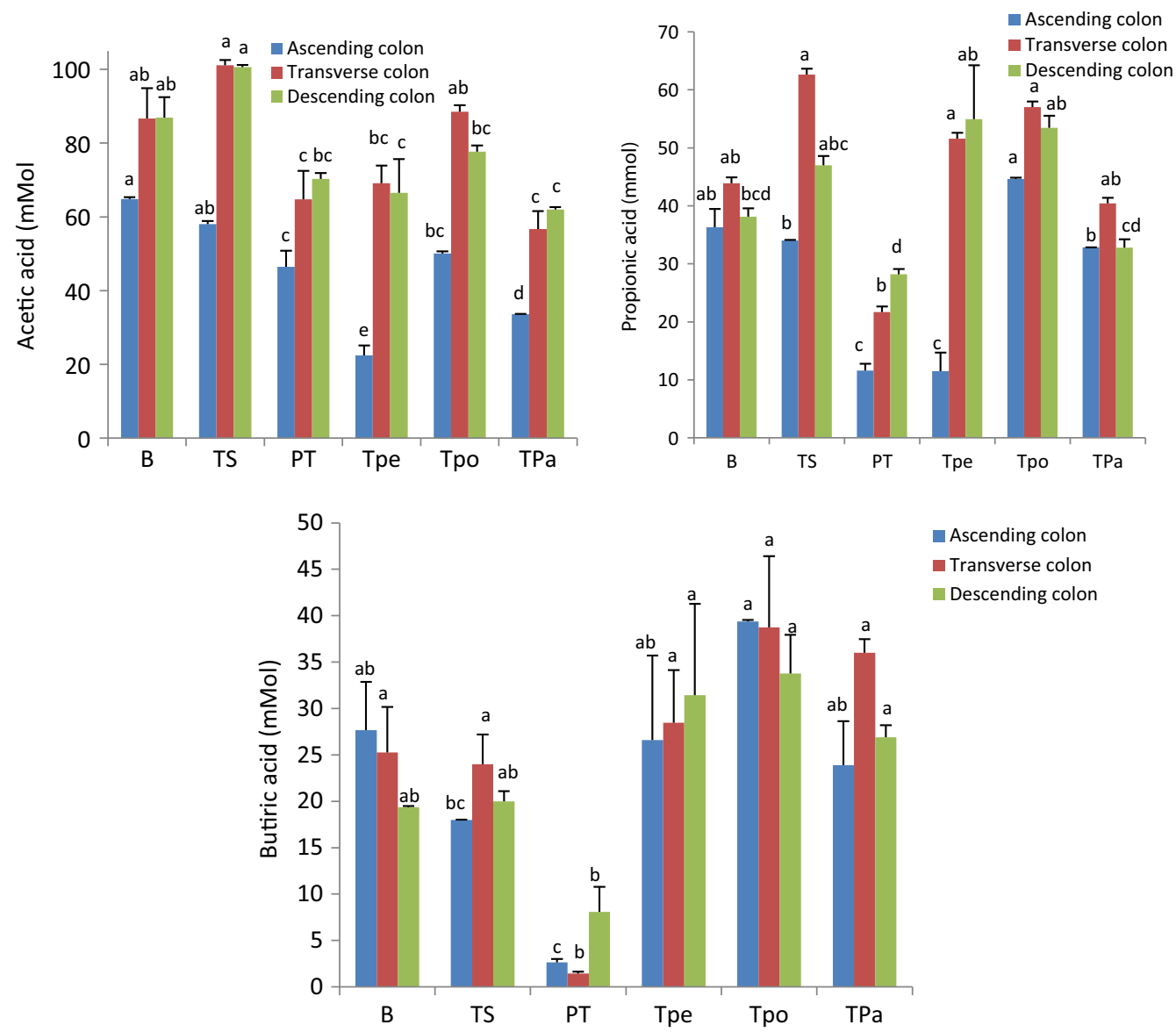

Ascending colon

- Transverse colon

Descending colon

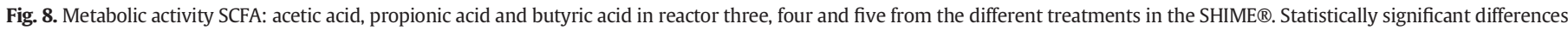

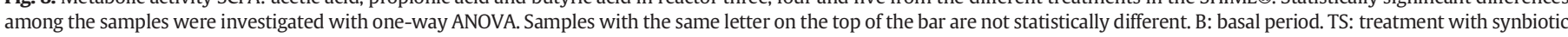
beverage, PT: post-treatment, Tpe: treatment with prebiotic beverage, Tpo: treatment with probiotic beverage and TPa: treatment with placebo beverage. 
Regarding the other beverages, there was a significant reduction in ammonia ions only in R3; however, this reduction was significantly lower when compared to the synbiotic beverage. There was no statistical difference among the prebiotic, probiotic and placebo beverages in any of the three compartments, but they were all statistically different from the synbiotic beverage. Kontula et al. (2002) found similar results when evaluating the effect of lactulose on Lactobacillus rhamnosus survival using the SHIME system, suggesting changes in the metabolic activity of the SHIME microbiota. In addition, similar effects with L. acidophilus LA5 in pressurized longan juice induced lower ammonia by $52.7,59.5$ and $50.4 \%$ in ascending, transverse, and descending colons, respectively, in comparison with the controls (Chaikham \& Apichartsrangkoon, 2014).

In this study, R3 and R5 showed the lowest and highest amounts of ammonia ions, respectively, independently of experimental period, corroborating Kontula et al. (2002), Possemiers et al. (2004) and Sivieri et al. (2011). According to Macfarlane, Gibson, and Cummings (1992), the concentration of ammonia in the intestinal lumen increases progressively from the ascending to the descending colon, which is related to a higher rate of protein fermentation in the descending colon compared to the ascending colon (Davila et al., 2013). Smith and Macfarlane (1998) attributed the lower production of ammonia from the ascending colon to low $\mathrm{pH}$ and high carbohydrate availability in this compartment.

\subsection{Analysis of short-chain fatty acids (SCFAs)}

No significant increase in the SCFA production in the colon compartments was observed during treatments compared to the basal period (Fig. 8). Although the FOS and probiotic L. casei Lc-01 stimulated (in combination or not) the growth of other Lactobacillus species, this stimulation was not sufficient to increase the production of SCFA, because the reactors had a limited amount of nutrients. Lactobacillus are saccharolytic microorganisms and produce lactate, ethanol and succinate as fermentation products, which are intermediates in the global fermentation process in the microbiota, being metabolized to SCFA by cross-feeding species in the ecosystem. Generally, these SCFAs do not accumulate in the intestine due to low or insufficient production (Macfarlane \& Macfarlane, 2003). These microorganisms cannot continue their normal cycle in the lack of nutrients, thereby reducing SCFA accumulation.

SCFA concentrations are a temporary state, because the majority of SCFA formed during the fermentation will be immediately used by colonocytes or other intestinal bacteria (Topping \& Clifton, 2001). According to Macfarlane and Gibson (1994), the formation of SCFA in the gut depends on various factors. From a microbiological viewpoint, the chemical composition, physical form and amount of substrate available affect bacterial fermentation reactions, which are also dependent on the types and numbers of different bacterial populations found in the gut, catabolite regulatory mechanisms, the availability of inorganic electron donors, as well as competitive and cooperative interactions between different species in the microbiota (Allison \& Macfarlane, 1988; Macfarlane \& Gibson, 1994).

\section{Conclusions}

The new beverage, based on aqueous extracts of quinoa and soy and fortified by L. casei Lc-01 and the prebiotic FOS, had the greatest beneficial action on the intestinal microbiota. The synbiotic beverage showed more significant effects in the ascending colon, increasing Lactobacillus spp. and Bifidobacterium spp. populations and reducing detrimental genera to the host, such as Bacteroides and Clostridium spp. It also significantly reduced production of ammonia ions in this compartment, and improved the diversity and richness of the Lactobacillus spp. community without affecting its functionality. Although the prebiotic and probiotic beverages had good results regarding the increase of commensal bacteria, the reduction of ammonia ions and pathogenic bacteria, these results were not as satisfactory as those provided by the synbiotic beverage. Therefore, the synbiotic beverage is a good matrix candidate for the intestinal delivery of probiotics, which helps the indigenous microbiota to improve human health.

\section{Acknowledgments}

The authors would like to acknowledge the Fundação de Amparo à Pesquisa do Estado de São Paulo (FAPESP) for the financial support given to this project no. 2011/08110-4.

\section{References}

Allison, C., \& Macfarlane, G. T. (1988). Effect of nitrate on methane production and fermentation in slurries of human faecal bacteria. Journal of General Microbiology, 134, 1397-1405

Ando, H., Chen, Yi-chun, Tang, H., Shimizu, M., Watanabe, K., \& Mitsunaga, T. (2002). Food components in fractions of quinoa seed. Food Science and Technology Research, 8 , $80-84$.

Bedani, R. (2008). Influência do consumo de "iogurte" de soja fermentado com Enterococcus faecium CRL 183 na microbiota intestinal de animais e humanos. (M.Sc. Dissertation). Araraquara, São Paulo, Brasil: Faculdade de Ciências Farmacêuticas, UNESP, 140.

Brigidi, P., Vitali, B., Swennen, E., Bazzocchi, G., \& Matteuzzi, D. (2001). Effects of probiotic administration upon the composition and enzymatic activity of human fecal microbiota in patients with irritable bowel syndrome or functional diarrhea. Research in Microbiology, 152, 735-774.

Capela, P., Hay, T. K. C., \& Shah, N. P. (2006). Effect of cryoprotectants, prebiotics and microencapsulation on survival of probiotic organisms in yoghurt and freeze-dried yoghurt. Food Research International, 39, 203-211.

Carballa, M., Smits, M., Etchebehere, C., Boon, N., \& Verstraete, W. (2011). Correlations between molecular and operational parameters in continuous lab-scale anaerobic reactors. Applied Microbiology and Biotechnology, 89, 303-314.

Chaikham, P., \& Apichartsrangkoon, A. (2014). Effects of encapsulated Lactobacillus acidophilus along with pasteurized longan juice on the colon microbiota residing in a dynamic simulator of the human intestinal microbial ecosystem. Applied Microbiology and Biotechnology, 8, 485-495.

Davila, A. -M., Blachiera, F., Gotteland, M., Mireille Andriamihaja, M., Benettia, P. -H., Sanzc, Y., et al. (2013). Intestinal luminal nitrogen metabolism: Role of the gut microbiota and consequences for the host. Pharmacological Research, 68, 95-107.

De Boever, P., Deplancke, B., \& Verstraete, W. (2000). Fermentation by gut microbiota cultured in a Simulator of the human intestinal microbial ecosystem is improved by supplementing a soygerm powder. Journal of Nutrition, 130, 2599-2606.

Desai, A. R., Powell, I. B., \& Shah, N. P. (2004). Survival and activity of probiotic lactobacilli in skim milk containing prebiotics. Journal of Food Science, 69, 57-60.

Edlund, C., Beyer, G., Hiemer-Bau, M., Ziege, S., Lode, H., \& Nord, C. E. (2000). Comparative effects of mixifloxacin and clarithromycin on normal intestinal microflora. Scandinavian Journal of Infectious Diseases, 32, 81-85.

Frick, J. S., \& Autenrieth, I. B. (2013). The gut microflora and its variety of roles in health and disease. Current Topics in Microbiology and Immunology, 358, 273-289.

Gilliland, S. E. (1987). Importance of bile tolerance in lactobacilli used as dietary adjunct. In T. P. Lyons (Ed.), Biotechnology in the feed industry (pp. 149-155). Lexingto: Alltech Feed Co.

Guergoletto, K. B., Magnani, M., Martin, J. S., Andrade, C. G. T. J., \& Garcia, S. (2010). Survival of Lactobacillus casei (LC-1) adhered to prebiotic vegetal fibers. Innovative Food Science and Emerging Technologies, 11, 415-421.

Heilig, H. G., Zoetendal, E. G. Vaughan, E. E., Marteau, P., Akkermans, A. D. \& De vos, W. M. (2002). Molecular diversity of Lactobacillus spp. and other lactic acid bacteria in the human intestine as determined by specific amplification of 16S ribosomal DNA. Applied and Environmental Microbiology, 68, 114-123.

Ichikawa, H., \& Sakata, T. (1998). Stimulation of epithelial cell proliferation of isolated distal colon of rats by continuous colonic infusion of ammonia or short-chain fatty acids is nonadditive. Journal of Nutrition, 128, 843-847.

Kontula, P., Nollet, L., Saarela, M., Vilpponen-Salmela, T., Verstraete, W., MattilaSandholm, T., et al. (2002). The effect of lactulose on the survival of Lactobacillus rhamnosus in the simulator of the human intestinal microbial ecosystem (SHIME $囚$ ) and in vivo. Microbial Ecology in Health and Disease, 14, 90-96.

Livingston, S. J., Kominos, S. D., \& Yee, R. B. (1978). New medium for selection and presumptive identification of Bacteroides fragilis group. Journal of Clinical Microbiology, 7, 448-453.

Lorenz, M. O. (1905). Methods of measuring concentration of wealth. Journal of the American Statistical Association, 9, 209-219.

Macfarlane, G. T., \& Gibson, G. R. (1994). Metabolic activities of the normal colonic flora. In S. Gibson (Ed.), Human health: The contribution of microorganisms (pp. 17-52). London: Springer.

Macfarlane, G. T., Gibson, G. R., \& Cummings, J. H. (1992). Comparison of fermentation reactions in different regions of the human colon. Journal of Applied Bacteriology, 72, $57-64$.

Macfarlane, S., \& Macfarlane, G. T. (2003). Regulation of short-chain fatty acid production. Proceedings of the Nutrition Society, 62, 67-72.

Marzorati, M., Verhelst, A., Luta, G., Sinnott, R., Verstraete, W., Van de Wiele, T., et al. (2010). In vitro modulation of the human gastrointestinal microbial community by 
plant-derived polysaccharide-rich dietary supplements. International Journal of Food Microbiology, 139, 168-176.

Marzorati, M., Wittebolle, L., Boon, N., Daffonchio, D., \& Verstraete, W. (2008). How to get more out of molecular fingerprints: Practical tools for environmental microbiology. Environmental Microbiology, 10, 1571-1581.

Marzotto, M., Maffeis, C., Paternoster, T., Ferrrario, R., Rizzotti, L., Pellegrino, M., et al. (2006). Lactobacillus paracasei A survives gastrointestinal passage and affects the fecal microbiota of healthy infants. Research in Microbiology, 157, 857-866.

Mertens, B., Boon, N., \& Verstraete, W. (2005). Stereospecific effect of hexachlorocyclohexane on activity and structure of soil methanotrophic communities. Environmental Microbiology, 7, 660-669.

Mills, S., Stanton, C., Fitzgerald, G. F., \& Ross, R. P. (2011). Enhancing the stress responses of probiotics for a lifestyle from gut to product and back again. Microbial Cell Factories, $10,1-19$.

Mishra, V., \& Prasad, D. N. (2005). Application of in vitro methods for selection of Lactobacillus casei strains as potential probiotics. International Journal of Food Microbiology, 103, 109-115.

Molly, K., De Smet, I., Nollet, L., De Woestyne, V., \& Verstraete, W. (1996). Effect of lactobacilli on the ecology of the gastro-intestinal microbiota cultured in the SHIME reactor. Microbiol Ecology in Health and Disease, 9, 79-89.

Molly, K., Vandewoestyne, M., Desmet, I., \& Verstraete, W. (1994). Validation of the simulator of the human intestinal microbial ecosystem (SHIME) reactor using microorganism associated activities. Microbial Ecology in Health and Disease, 7, 191-200.

Munoa, F. J., \& Pares, R. (1988). Selective medium for isolation and enumeration of Bifidobacterium spp. Applied and Environmental Microbiology, 54, 1715-1718.

Payne, S., Gibson, G., Wynne, A., Hudspith, B., Brostoff, J., \& Tuohy, K. (2003). In vitro studies on colonization resistance of the human gut microbiota to Candida albicans and the effects of tetracycline and Lactobacillus plantarum LPK. Current Issues in Intestinal Microbiology, 4, 1-8.

Payne, A. N., Zihler, A., Chassard, C., \& Lacroix, C. (2012). Advances and perspectives in in vitro human gut fermentation modeling. Trends in Biotechnology, 30, 17-25.

Possemiers, S., Marzorati, M., Verstraete, W., \& Van de Wiele, T. (2010). Bacteria and chocolate: A successful combination for probiotic delivery. International Journal of Food Microbiology, 141, 97-103.

Possemiers, S., Verthé, K., Uyttendaele, S., \& Verstraete, W. (2004). PCR-DGGE-based quantification of stability of the microbial community in a simulator of the human intestinal microbial ecosystem. FEMS Microbiology Ecology, 49, 495-507.

Pozza, M. S. S., Miglioranza, L. H. S., Garcia, J. E., Garcia, S., \& Pozza, P. C. (2011). Human gastrointestinal tract resistance of Lactobacillus strains isolated from infant faeces. Semina: Ciências Agrárias, 32, 1021-1032.

QIAGEN (2010). QIAamp® DNA Stool Handbook (2th ed.) (http://www.qiagen.com).

Rajilic-Stojanovic, M., Smidt, H., \& De vos, W. M. (2007). Diversity of the human gastrointestinal tract microbiota revisited. Environmental Microbiology, 9, 2125-2136.
Rossi, E. A., Reddy, K. V., \& Silva, R. S. S. F. (1984). Formulation of soy-whey yogurt, using response surface methodology. Brazilian Archives of Biology and Technology, 27. 387-390.

Rossi, E. A., Vendramine, R. C., Carlos, I. Z., Pei, Y. C., \& Valdez, G. F. (1999). Development of a novel fermented soymilk product with potential probiotic properties. European Food Research and Technology, 209, 305-307.

Saarela, M., Mogensen, G., Fondén, R., Matto, J., \& Mattila-Sandholm, T. (2000). Probiotic bacteria: Safety, functional and technological properties. Journal of Biotechnology, 84, 197-215.

Sanguinetti, C. J., Dias Neto, E., \& Simpson, A. J. G. (1994). Rapid silver staining and recovery of PCR products separated on polyacrylamide gels. Biotechniques, 17, 915-919.

Sivieri, K., Bianchi, F., \& Rossi, E. A. (2011). Fermentation by gut microbiota cultured in a simulator of the human intestinal microbial ecosystem is improved probiotic Enterococcus faecium CRL 183. Functional Foods in Health and Disease, 10, 389-402.

Sivieri, K. Morales, M. L. V., Adorno, M. A. T., Sakamoto, I. K. Saad, S. M. I., \& Rossi, E. A. (2013). Lactobacillus acidophilus CRL 1014 improved "gut health" in the SHIME® reactor. Gastroenterology, 13, 100-109.

Smith, E. A., \& Macfarlane, G. T. (1998). Enumeration of amino acid fermenting bacteria in the human large intestine: effects of $\mathrm{pH}$ and starch on peptide metabolism and dissimilation of amino acids. FEMS Microbiology Ecology, 25, 355-368.

Topping, D. L., \& Clifton, P. M. (2001). Short-chain fatty acids and human colonic function: Roles of resistant starch and nonstarch polysaccharides. Physiological Reviews, 81, 1031-1064.

Van de Wiele, T., Boon, N., Possemiers, S., Jacobs, H., \& Verstraete, W. (2004). Prebiotic effect of chicory inulin in the simulator of the human intestinal microbial ecosystem. FEMS Microbiology Ecology, 51, 143-153.

Van de Wiele, T., Boon, N., Possemiers, S., Jacobs, H., \& Verstraete, W. (2007). Inulin-type fructans of longer degree of polymerization exert more pronounced in vitro prebiotic effects. Journal of Applied Microbiology, 102, 452-460.

Vega-Gálvez, A., Miranda, M., Vergara, J., Uribe, E., Puente, I., \& Martínez, E. A. (2010) Nutrition facts and functional potential of quinoa (Chenopodium quinoa willd.), an ancient Andean grain: A review. Journal of the Science of Food and Agriculture, 90, 2541-2547.

Wittebolle, L., Vervaeren, H., Verstraete, W., \& Boon, N. (2008). Quantifying community dynamics of nitrifiers in functionally stable reactors. Applied and Environmental Microbiology, 74, 286-293.

Woodmansey, E. J. (2007). Intestinal bacteria and ageing. Journal of Applied Microbiology, $102,1178-1186$

Xanthopoulos, V., Litopoulou-Tanetaki, E., \& Tzanetakis, N. (2000). Characterization of Lactobacillus isolates from infant faeces as dietary adjuncts. Food Microbiology, 17, 205-215.

Yoshioka, H., Iseki, K., \& Fujita, K. (1983). Development and difference of intestinal flora in the neonatal period in breast-fed and bottle-fed infants. Pediatrics, 72, 317-321. 